\title{
A Food-Energy-Water Nexus approach for land use optimization
}

DOI:

10.1016/j.scitotenv.2018.12.242

\section{Document Version}

Accepted author manuscript

Link to publication record in Manchester Research Explorer

\section{Citation for published version (APA):}

Nie, Y., Avraamidou, S., Xiao, X., Pistikopoulos, E. N., Li, J., Zeng, Y., Song, F., Yu, J., \& Zhu, M. (2019). A FoodEnergy-Water Nexus approach for land use optimization. Science of the Total Environment, 659, 7-19. https://doi.org/10.1016/j.scitotenv.2018.12.242

\section{Published in:}

Science of the Total Environment

\section{Citing this paper}

Please note that where the full-text provided on Manchester Research Explorer is the Author Accepted Manuscript or Proof version this may differ from the final Published version. If citing, it is advised that you check and use the publisher's definitive version.

\section{General rights}

Copyright and moral rights for the publications made accessible in the Research Explorer are retained by the authors and/or other copyright owners and it is a condition of accessing publications that users recognise and abide by the legal requirements associated with these rights.

\section{Takedown policy}

If you believe that this document breaches copyright please refer to the University of Manchester's Takedown Procedures [http://man.ac.uk/04Y6Bo] or contact uml.scholarlycommunications@manchester.ac.uk providing relevant details, so we can investigate your claim.

\section{OPEN ACCESS}




\title{
A Food-Energy-Water Nexus approach for land use optimization
}

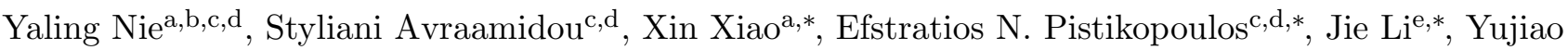 \\ Zeng $^{\mathrm{a}}$, Fei Song ${ }^{\mathrm{a}}$, Jie $\mathrm{Yu}^{\mathrm{a}}$, Min $\mathrm{Zhu}^{\mathrm{a}}$ \\ ${ }^{a}$ Institute of Process Engineering, Chinese Academy of Sciences, Beijing 100190, China \\ ${ }^{b}$ University of Chinese Academy of Sciences, Beijing 100049, China \\ ${ }^{c}$ Artie McFerrin Department of Chemical Engineering, Texas A \& M University, College Station, TX 77843, USA \\ ${ }^{d}$ Texas A \& M Energy Institute, Texas A \& M University, College Station, TX 77843, USA \\ ${ }^{e}$ School of Chemical Engineering and Analytical Science, The University of Manchester, Manchester M13 9PL, UK
}

\section{Abstract}

Allocation and management of agricultural land is of emergent concern due to land scarcity, diminishing supply of energy and water, and the increasing demand of food globally. To achieve social, economic and environmental goals in a specific agricultural land area, people and society must make decisions subject to the demand and supply of food, energy and water (FEW). Interdependence among these three elements, the Food-Energy-Water Nexus (FEW-N), requires that they be addressed concertedly. Despite global efforts on data, models and techniques, studies navigating the multi-faceted FEW-N space, identifying opportunities for synergistic benefits, and exploring interactions and trade-offs in agricultural land use system are still limited. Taking an experimental station in China as a model system, we present the foundations of a systematic engineering framework and quantitative decisionmaking tools for the trade-off analysis and optimization of stressed interconnected FEW-N networks. The framework combines data analytics and mixed-integer nonlinear modeling and optimization methods establishing the interdependencies and potentially competing interests among the FEW elements in the system, along with policy, sustainability, and feedback from various stakeholders. A multiobjective optimization strategy is followed for the trade-off analysis empowered by the introduction of composite FEW-N metrics as means to facilitate decision-making and compare alternative process and technological options. We found the framework works effectively to balance multiple objectives and benchmark the competitions for systematic decisions. The optimal solutions tend to promote the food production with reduced consumption of water and energy, and have a robust performance with alternative pathways under different climate scenarios.

Keywords: land use, Food-Energy-Water Nexus, data-driven modeling, multi-objective optimization, integrated assessment

\footnotetext{
* Corresponding author

Email addresses: xxiao@ipe.ac.cn (Xin Xiao), stratos@tamu.edu (Efstratios N. Pistikopoulos), jie.li-2@manchester.ac.uk (Jie Li )
} 


\section{Introduction}

Agricultural land is the largest ecosystem to provide food for human (Ellis \& Ramankutty, 2008). Agricultural production accounts for $\sim 30 \%$ of the global energy consumption, $\sim 92 \%$ of the human water footprint, and over $20 \%$ of global greenhouse gas emissions (Alexandratos et al., 2012; Sims, 2011). The Food and Agricultural Organization (FAO) estimates a $~ 60 \%$ increase of food demand (compared with that of $2005 / 2007$ ) for feeding 9.7 billion people by 2050 , but the contribution of cropland expansion to the increase is expected to reduce from $14 \%$ to $10 \%$ due to environmental reasons at that time (Alexandratos et al., 2012; Ramankutty et al., 2018). Several countries, particularly in the Near East/North Africa and South Asia, have already reached or are close to the limits of land resource $(\mathrm{FAO}, 2009)$. Thus, there is an increasing pressure to meet the food demand of current and future human populations with limited land expansion while minimizing the consumption of energy and water and conserving the environment.

Typically, agricultural food production is a water and energy intensive process, for instance, water is used for irrigation, energy is used as power or fertiliser source during production, and there are also land competitions among food crop and energy crop. Therefore, for specific land use system, the decisions to meet both human needs and nature conservation goals are subject to the demand and supply of food, energy and water (FEW), and can be dealt with optimization techniques (Bergstrom et al., 2013; Rathmann et al., 2010; Beinat \& Nijkamp, 1998). Due to the interdependence among FEW, which is commonly referred to as the Food-Energy-Water Nexus (FEW-N) (Keairns et al., 2016; Scanlon et al., 2017), unbiased decisions require that they should be addressed concertedly. That is, for the land use optimization problem, solutions considering Nexus scope rather than individual FEW elements would provide more sustainable decisions due to the very nature of FEW nexus in land use systems. In addition, the land-specific optimal decisions will provide optimal FEW Nexus for individual production sectors in the system, which will improve productivity and develop more efficient resource management. Accordingly, the FEW Nexus for the land use optimization problem offers a promising conceptual method to identify trade-offs and integration effort of FEW elements in the system (D'Odorico et al., 2018).

To identify unbiased decisions and interactions of FEW elements in the systems, methodologies of current nexus studies mainly include data-intensive modeling for geographical land area, life cycle analysis for specific technologies or products, and systematic analysis based on descriptive methods (Keairns et al., 2016; Albrecht et al., 2018). These nexus methods provide essential knowledge and useful approaches for expanding our understanding of FEW interactions and addressing social and 
economic concerns of FEW related systems.

Yet to achieve a quantitative understanding of the FEW-N interrelationships and make optimal holistic decisions, it is required to solve challenges including predictive modeling approaches, effective integration of data and models, optimization methods for exploring and evaluating trade-offs, and generic metrics for assessing FEW interlinkages in the systems (Mohtar \& Daher, 2018; Sayer et al., 2013; D'Odorico et al., 2018; Ramankutty et al., 2018).

A fundamental challenge for optimal decision-making is the predictive modeling approaches (McCarl et al., 2017b,a; Holzworth et al., 2015; van Ittersum et al., 2013). To represent components in a land use system, many studies have focused on the modeling aspect of crop and livestock production systems, models including DSSAT (Jones et al., 2003), APSIM (Keating et al., 2003), and AquaCrop (Steduto et al., 2009) have improved our ability to predict the productivity gains of crop or livestock in scientific understanding and data availability. In general, these kinds of models are often described as large sets of sub-models or equations, and take into consideration many factors, such as climate change and biological properties for different objectives (Nelson et al., 2014). However, increasing considerations may also result to more data input, more parameters, and therefore more complicated models. Such consideration may increase the need for more available data and region-specific and/or crop-specific parameters (Paul et al., 2017), which may not be really available to most developing countries. All of these underlying uncertainties will cause changes in land use systems, which must be merged to the learning process for better decision-making (Vermeulen et al., 2013). Hence, it is important to consider data limitations and adaptive strategies for modeling productivity in the land use systems.

In addition, from a process systems engineering perspective, systematic decisions require efficient and quantitative integration methods for data and models (Bertran et al., 2017; Jones et al., 2017b). In agricultural systems with multiple production units involving large amounts of FEW data and potential pathways, a family of available models are needed to represent these complex relations in the production processes. Comparisons of ultimate results also require model integration from each process. All of these integrations will lead to low computational efficiency in a complex land use system (Jones et al., 2017a). Therefore, effective integration methods for data management, alternatives generation, and flexible modeling in land use systems are urgently needed.

Another major challenge in agricultural land use arises from the presence of multiple stakeholders and their differing, and often conflicting, objectives such as profit, food demand, environmental goals, and efficient use of resources (e.g., water and energy) (Stewart et al., 2004; Garcia \& You, 2016). Thus, the problem of land use optimization is often studied as a multi-objective optimization problem 
(Seppelt, 2016). Despite multi-objective optimization techniques, such as the $\varepsilon$-constraint method, can effectively reach the best compromise when the bounds of objective functions are known, and has been used in FEW related systems (Uen et al., 2018; Dhaubanjar et al., 2017; Zhang et al., 2018), it is critically difficult to get trade-offs while facing large amounts of uncertainties and complicated interactions in land use systems (Chiandussi et al., 2012).

When considering FEW Nexus wide decision-making approaches, more challenges emerge including the identification of interactions among the FEW elements (Flammini et al., 2017; Mohtar et al., 2019; El-Gafy, 2017; Dargin et al., 2018), the resilience decision-making for climate change (Van Tra et al., 2018), and the conflicts between stakeholders' interests and environmental impacts (Song et al., 2018). These challenges can limit progress towards improved FEW resources management, trade-off decisions, and sustainable outcomes across different production sectors. Although the importance of addressing systematic uncertainties is well acknowledged, few studies have generic and quantitative metrics for decision-making in land use systems (Albrecht et al., 2018; Daher et al., 2018).

All the above challenges raise a need for the development of robust and systematic methods to derive trade-offs for land use decision-making. In this study, we propose a three-step framework, especially targets at the development of novel workflows and data flows for generic land distribution in the context of effective integration of FEW-N related data, models and optimization methods. As a result, the framework can output a flexible superstructure for designing the land use system with effective integration of data and models, a family of adaptable models for representing the production processes with limited data and adaptation strategies, and a mixed integer nonlinear programming (MINLP) model along with adjustable FEW-based metrics for solving the multi-objective decisionmaking problem and assessing different solutions. Operational decisions from the framework include the production and use of food, energy and water in the production process for each production unit that can trade-off conflicted objectives. Our framework can assist policy-makers by supplying them with quantitative assessment of solutions for different objectives, as well as provide actionable pathways to meet economic goals with reduced environmental concerns.

\section{Case study area}

As a case study of our approach, we select Yucheng Station $\left(36.96^{\circ} N, 116.63^{\circ} \mathrm{E}\right)$, an experimental station belonging to Chinese Academy of Sciences, as the land use system. Yucheng Station is located in Yucheng County, Shandong Province of China, which is a typical agricultural county in the North China Plain (NCP). In this region, grain and cotton are the main crops, while agriculture is 
experiencing an adjustment from single cropping to crop-livestock mixed farming system (Chen et al., 2012). Considering the local common choice, specific crops (wheat, corn and cotton) and livestock (cattle, hens and pig) are selected as the typical production units to construct the system. This land use system can be a typical example for the land use decision-making in NCP, as it has great support on local data and policies, and it also includes several similar characteristics, such as large demand of food, water scarcity, overuse of fertiliser, and serious water and soil pollution problems (Fang et al., 2006). We believe this framework will have the potential to become a widely used tool to optimize and benchmark agricultural land use systems.

\section{Material and methods}

Our framework requires three steps. 1) Superstructure design of land use allocation with dependencies on FEW. This step is used to identify the main features of the land use system, thus providing a base holistic design. 2) Unit modeling of production units, which provides generic simulations of the production processes and quantifies the FEW relations for basic production units in the system. 3) Multi-objective MINLP optimization. This last step translates the decision-making problem into a multi-objective MINLP problem by integrating the FEW data and unit models based on the proposed superstructure, and the problem can be efficiently solved with the help of a flexible and adjustable FEW metric. The structure summary is shown in Table 1, and the modeling framework is summarized in Fig. 1. Each step is discussed below, the data sources in the consideration area are shown in Supplementary Section 1.

\subsection{Step1: Superstructure design}

The goal of land allocation is to optimize the basic structure for a given area by considering land competitions among different production units. A generic land allocation structure is shown in Fig. 2, and it is constructed with a set of grids with two land types: cropland and livestock land. Land competitions not only exist between different land types, but also can appear among different production units within the same land types. The workflow for step 1 follows two sub-step: (1.1) Land use and FEW-Nexus definition, and (1.2) superstructure generation.

\subsubsection{Step 1.1: Problem definition based on FEW-Nexus}

This work is to provide a generic decision-making framework to maximize the trade-off benefits of the crop and livestock production in the land use system. In order to model the system, the 
Table 1: Structure summary for each step of the framework

\begin{tabular}{|c|c|c|c|}
\hline & Step 1 & Step 2 & Step 3 \\
\hline Problem features & Design & Modeling & Optimization \\
\hline \multirow[t]{5}{*}{ Input } & FEW-land supply/demand & Condition data set & Conditional unit models \\
\hline & climate conditions & FEW data flow & FEW-land constraints \\
\hline & process parameters & basic production units & optimization objectives \\
\hline & interest of stakeholders & & superstructure connections \\
\hline & policy and law & & a FEW-based metric \\
\hline \multirow[t]{6}{*}{ Output } & Condition data set & Conditional unit models & Optimal system designs \\
\hline & FEW data flow & & optimal FEW-land use \\
\hline & basic production units & & assessment of solutions \\
\hline & FEW-land constraints & & \\
\hline & optimization objectives & & \\
\hline & superstructure connections & & \\
\hline
\end{tabular}

following information should be specified: the objectives, the available FEW and land data sets, the production units set, the products set, the processing procedures, and the set of available technologies and operations.

In this study, according to the feedback of stakeholders and policy-makers, the optimization objectives includes total profit $(T P)$, total food production $(T F)$, total energy use $(T E)$, total water use $(T W)$, and total environmental penalty $(T E n)$ over a course of production years.

As shown in Fig. 2, the cultivation area includes two land types: cropland and livestock land, which are allocated to crop production units (wheat, corn, and cotton) and livestock production units (cattle, hens, and pig), respectively. Specifically, the production of wheat and corn can construct a rotation system in the consideration area since they can grow in the same area in sequenced seasons, that is, there is no land competition in the rotation system in one production year. The land area we study is divided into grids with different scales according to realistic production situations (Table S1 in Supplementary Section 1), then the FEW constraints for different production units are defined based on each grid.

All of the input-output data in the land use system include input FEW resources and output products and byproducts data from production units, economic data from social surveys, and other 


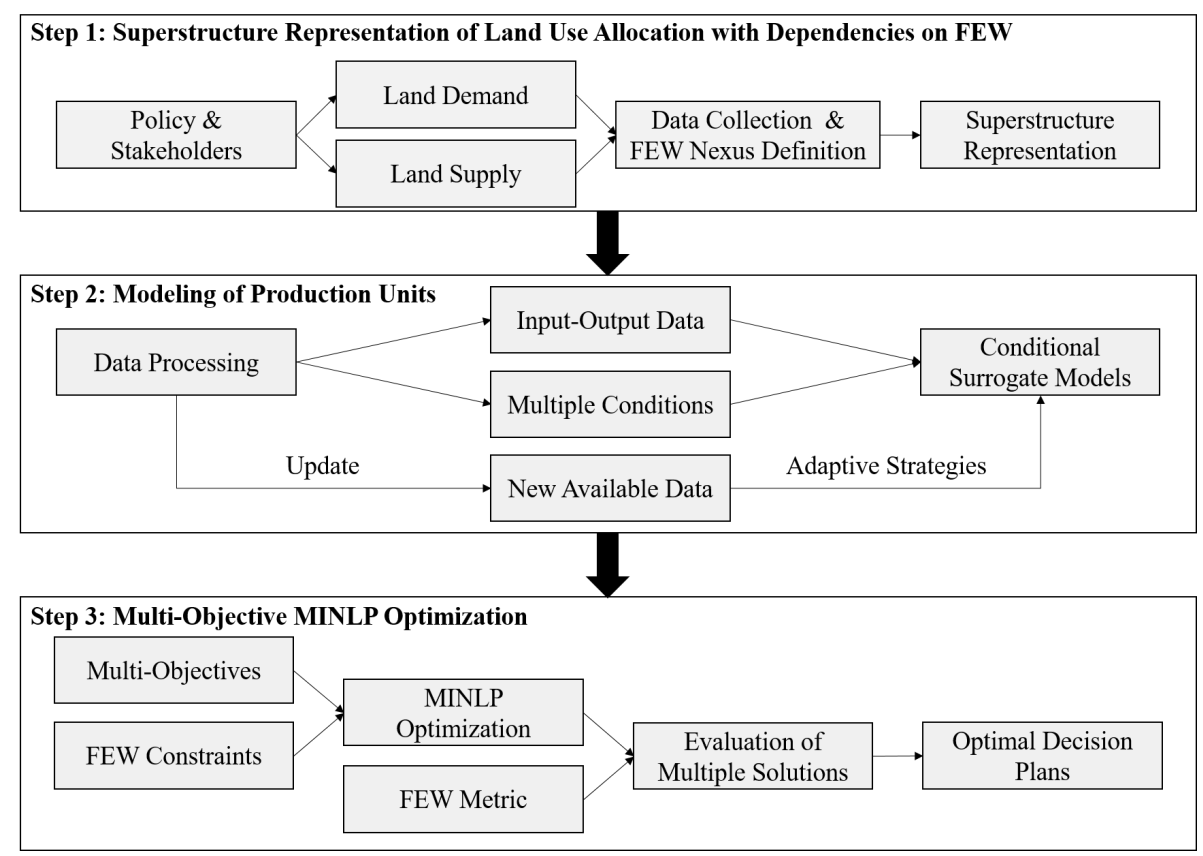

Figure 1: Framework for crop-livestock land use problem

data for dynamic conditions, such as climate data. These data are collected from various sources, for instance, the open literatures and databases, local experiments recordings and experts' experience (Supplementary Section 1). Some data, such as the original input-output FEW data for crop modeling, are not readily available, but can be generated by using the simulator APSIM (Keating et al., 2003). Then all these data are grouped based on the input-output FEW use and production by different production units, and the nexus is defined by quantifying the FEW flow sheet through them.

Alternative pathways that use different technologies are identified based on local availability. Specifically, considering crop production units, the main food output is crop products while straw is the main byproduct. The crop food produced by the wheat-corn rotation subsystem can be sold to market or sent to livestock land for feeding. The crop straw can have three routes: sell to market, return to cropland as an alternation of chemical fertiliser, or used as feed for cattle. Saline (low quality) and drinkable water (high quality) are set as the two choices for irrigation. To improve the efficiency of organic fertiliser, the biological technology such as fermentation can be an optional choice for manure return. Only drinkable water can be selected for livestock feeding.

Based on all the above known parameters and information, the framework need to make decisions including:

- production units selection for different land grids based on different climate conditions; 


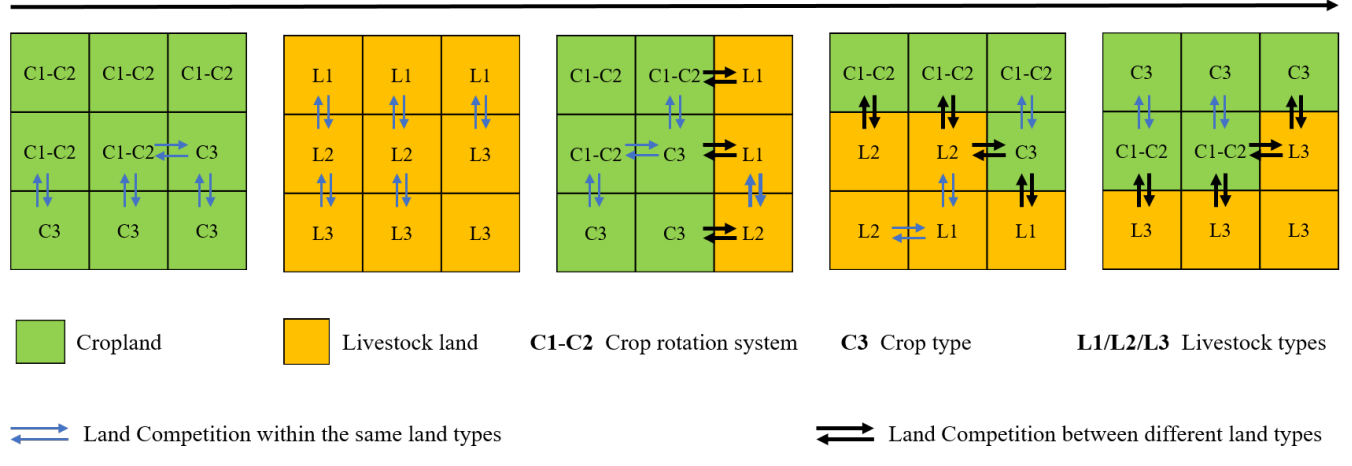

Figure 2: Problem definition of land allocation. In the consideration area, the typical growing season for wheat is from early October to the middle of the following June, and summer maize is planted at the end of winter wheat season and harvested in late September, therefore, the wheat and corn can be set as a rotation system, which don't have land competitions in one year.

- input-output FEW demand/supply for production units;

- sustainable pathways selection in the superstructure network;

- final product production and pathways for specific objectives and final trade-offs, given the boundaries of FEW, price, cost and specifications of the crop-livestock system;

- quantitative assessment for objective-related solutions.

\subsubsection{Step 1.2: Superstructure generation}

From the collected data and alternatives involved in the decision-making land use system, a superstructure is generated. Fig. 3 presents an example of a land use system network considering three different food crops and three livestock crops through a superstructure consisting of FEW resources, production units, land grids, products and byproducts, known technologies, and FEW-related operations that connect them. The superstructure also includes several alternative pathways for resource recycling in the system, such as supply resources of feed food, treatment of livestock waste, and routes for crop straw use. The size of the decision-making problem depends on the numbers of these elements in the superstructure, which can be flexible based on the scales of resources, units, land, and alternative technologies and operations. In this study, fertiliser and power use are taken as energy use, there is no energy production as we focus on agricultural land use optimization for food production. 


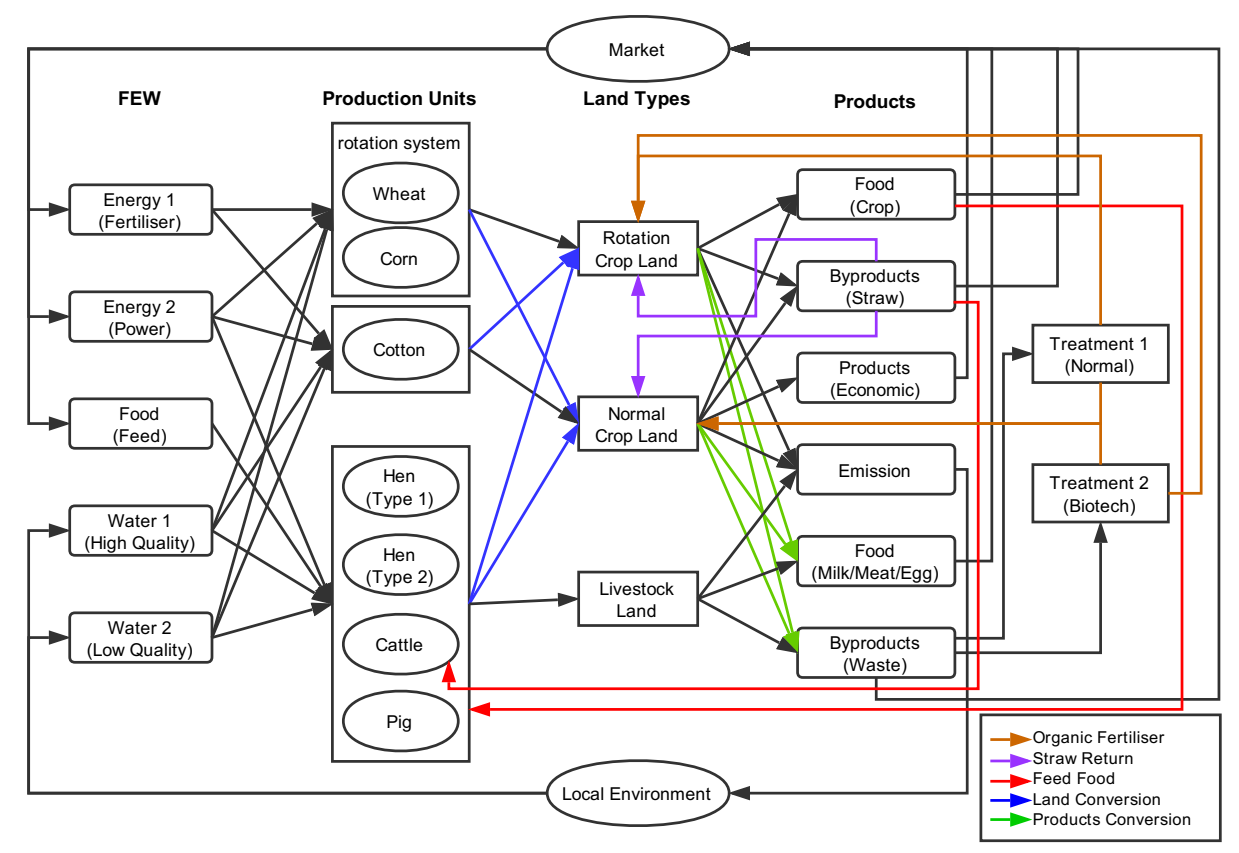

Figure 3: Initial superstructure representation for the crop-livestock land use system. For the difference of two treatment techniques, this study considers the additional cost of the biotechnology treatment (Table S5 and Supplementary Section 1).

\subsection{Step 2: Data-driven modeling}

In the modeling step (Step 2), input-output FEW relations are established for all the production units in the system based on surrogate models. For production units with high uncertainties, a datadriven modeling method is applied to surrogate the models. For other production units, a set of simple piecewise functions are used to approximate the production actions. The data-driven modeling method includes three sub-step: (2.1) input-output data set construction for different conditions, (2.2) parameter estimation for surrogate models based on conditional input-output data set, and (2.3) model improvement by using adaptation strategies. Here, the workflow of the data-driven modeling method are highlighted in Fig. S1.

\subsubsection{Step 2.1: Input-output data set construction for different conditions}

Climate change can significantly affect agricultural production (Asseng et al., 2013). Especially, taking the crop production as an example, different climate conditions will alter the potential crop yield with the same irrigation and fertilization schedules. In addition, the schedule of irrigation and 
fertilization during productions can also affect the potential yield even with the same water and fertiliser input at the same climate conditions. Thus, different climate condition data and schedule data can have many combinations, making it extremely difficult for us to obtain data for all the combinations from real production processes. To address the data limitation for modeling crop production units, a frequency analyse-based method is used to achieve the near-optimal schedules and construct the input-output data for modeling under different climate conditions. For each climate condition, a candidate schedule set can be constructed based on randomly selected operation times for irrigation and fertilization. Simulated experiments of a group of input data points (irrigation and fertiliser, $X$ ) are carried out through the simulator based on the schedule set. The near-optimal schedules $(S)$ for input water and fertiliser can be simply chosen through statistic analysis, that is, counting the frequency of schedules with maximum response food yield $y$ for each input data point, the schedules with maximum frequency are set as the good choices for crop production in the specific conditions (Details in Supplementary Section 2.1).

\subsubsection{Step 2.2: Parameter estimation for surrogate models based on conditional input-output data set}

Note the fact that no single type of surrogate model outperforms all other types for dissimilar processes, and choosing the best type of surrogates for each process is a challenging task (Linker \& Sylaios, 2016). In general, the surrogate model may have better performance by choosing a combination of different types of surrogate models rather than using just a single type of surrogate models (Bhosekar \& Ierapetritou, 2017).

In this step, a mix-weighted surrogate model is used to estimate the unit production model $M$. The types $(k \in K)$ of surrogate functions $f_{\theta}^{(k)}$ can be linear, quadratic and reference types, etc. (Frank et al., 1990; Wang \& Baerenklau, 2014). Thus, in this step the optimization problem of parameter estimation for weights $\omega_{k}$ and $\theta^{(k)}$ of surrogate model $\hat{F}_{\theta}$ is solved. By using the conditional inputoutput data set $\{X, y \mid S\}$, the proposed method can solve the surrogate modeling problem based on the OLS (Ordinary Least Square) approach (Montgomery et al., 2012), cross validation technique and a mix-weight method (Goel et al., 2007). Eq. 1 shows the general type of the surrogate models, and the detailed methods are in Supplementary Section 2.2.

$$
\hat{F}_{\theta}(X)=\sum_{k=1}^{3} \omega_{k} f_{\theta}^{(k)}(X)
$$




\subsubsection{Step 2.3: Model improvement by using adaptation strategies}

Though accurate surrogate models $M$ can be achieved by the above mentioned data-driven modeling methods based on accurate input-output data, available data for modeling are quite limited in reality (Humblot et al., 2017). To address this challenge, as the optimal surrogate model $M^{K}$ based on simulating experiments data is generated, an adaptation strategy based on new available data is designed to decrease the error ratios of surrogate models (see details in Supplementary Section 2.3 and Fig. S3) .

\subsection{Step 3: Multi-objective optimization and assessment}

Since the production units in the system can be described by the proposed modeling methods in step 2, a family of unit models are developed to predict their yields. Based on the collected FEW data, we can define the land use problem as a multi-objective MINLP problem, and solve it with two sub-step: (3.1) Mathematical Formulations for the Multi-Objective Problem, (3.2) MINLP Problem Solving and Assessing Based on the FEW Metric.

\subsubsection{Step 3.1: Mathematical Formulations for the Multi-Objective Problem}

The five different objectives for the system are given in Eq. 2: maximal profit (TP), maximal food yield $(T F)$, minimal energy use $(T E)$, minimal water use $(T W)$ and minimal environmental penalty $(T E n)$. Each individual objective can be solved directly to optimality using the global MINLP solver ANTIGONE in GAMS (Misener \& Floudas, 2014) (see details in Supplementary Section 3). 


$$
\begin{aligned}
& \max T P=\sum_{c \in C} \sum_{a \in A}\left(p_{c} F_{c a}-T C_{c a}\right)+\sum_{l \in L} \sum_{b \in B}\left(p_{l} F_{l b}-T C_{l b}\right) \\
& \max T F=\sum_{c \in C} \sum_{a \in A} F_{c a}+\sum_{l \in L} \sum_{b \in B} F_{l b}-\sum_{b \in B} F_{1 b}^{\prime} \\
& \min T E=\sum_{c \in C} \sum_{a \in A}\left(E_{c a}-E_{c a}^{\prime}\right)+\sum_{l \in L} \sum_{b \in B}\left(E_{l b}-E_{l b}^{\prime}\right) \\
& \min T W=\sum_{c \in C} \sum_{a \in A} W_{c a}+\sum_{l \in L} \sum_{b \in B} W_{l b} \\
& \min T E n=\sum_{c \in C} \sum_{a \in A} E n_{c a}+\sum_{l \in L} \sum_{b \in B} E n_{l b}
\end{aligned}
$$

s.t.

$$
\begin{aligned}
& T F \geq T F^{l o} \\
& T W^{l o} \leq T W \leq T W^{u p} \\
& T E^{l o} \leq T E \leq T E^{u p} \\
& y^{r} \in\{0 ; 1\} ; r \in R
\end{aligned}
$$

where $c \in C$ and $l \in L$ are production units of crop $(C)$ and livestock $(L)$, respectively. $a \in A$ and $b \in B$ represent cropland grids and livestock land grids. These objectives are calculated based on energy $\left(E_{c a}, E_{l b}\right)$, water use $\left(W_{c a}, W_{l b}\right)$, economic cost $\left(T C_{c a}, T C_{l b}\right)$, environmental penalty $\left(E n_{c a}, E n_{l b}\right)$, and yield output $\left(F_{c a}, F_{l b}\right)$ from different land grids. The total cost for production units $(T C)$ includes their related constant cost, energy cost, water cost and other cost (e.g. biotechnology, labor, etc.) (Table S5). The energy use for production $(E)$ is the combination of fertiliser, pesticide, irrigation, diesel and feed. The water use $(W)$ mainly comes from irrigation and livestock feeding. The environmental penalty $(E n)$ in this study only considers the carbon emission and nitrogen leakage . As the framework supposes to provide solutions over production years, by choosing recycling pathways, the previous crop production in the system can supply part of the food consumed in the livestock production units $\left(F_{1 b}^{\prime}\right)$, and the previous wastes $\left(E_{c a}^{\prime}\right.$ and $\left.E_{l b}^{\prime}\right)$ generated in the crop and livestock production can be converted to organic fertiliser used in the crop production, which are regarded as new sources for energy use (the fertiliser ratios of waste are shown in Table S3, and the corresponding energy intensities are shown in Table S4). Defining appropriate boundaries for any FEW Nexus related systems is a challenge, as the FEW Nexus is broad and complex in time and space aspect. Narrow boundaries for the system will miss some key impacts, while broad boundaries will increase the model complexity. In this case, we define the system boundaries by considering the production on the pieces of land rather than the 
whole supply chains. The constraints include FEW constraints $(T F, T E, T W)$ with lower bounds (lo) and upper bounds $(u p)$, the binary variables $y^{r}$ with several choices of land allocation ( $\left.y^{\text {land}}\right)$, water quality $\left(y^{\text {saltW}}\right)$, byproducts reuse $\left(y^{\text {return }}\right)$ and biotechnology treatments $\left(y^{\text {bio }}\right)$ (Eq. S8 to S12) in the system.

\subsubsection{Step 3.2: MINLP Problem Solving and Assessing Based on the FEW Metric}

Each individual objective in Eq. 2 can be solved directly to optimality using global MINLP solvers through GAMS (Misener \& Floudas, 2014). A set of indicators is defined as a FEW metric for them (Eq. 3), these indicators quantify each of the objectives (decision elements) from different stakeholders, which provide multiple criterions for decision-makers. The decision-makers decide the quantities that best describe each of the decision elements. Those indicators can heavily dependent on the choice of the system boundary.

$$
\begin{aligned}
P_{s c} & =\frac{T P-T P_{\min }}{T P_{\max }-T P_{\min }} \\
F_{s c} & =\frac{T F-T F_{\min }}{T F_{\max }-T F_{\min }} \\
E_{s c} & =1-\frac{T E-T E_{\min }}{T E_{\max }-T E_{\min }} \\
W_{s c} & =1-\frac{T W-T W_{\min }}{T W_{\max }-T W_{\min }} \\
E n_{s c} & =1-\frac{T E n-T E n_{\min }}{T E n_{\max }-T E n_{\min }}
\end{aligned}
$$

where $P_{s c}, F_{s c}, E_{s c}, W_{s c}$ and $E n_{s c}$ are the indexes for five objective functions in Eq. 2, respectively and selected here as decision elements. Before calculating these indexes, true boundaries for them can be calculated by solving the corresponding individual objective optimization problem. For instance, for the index $P_{s c}$, the maximal and minimal objective determined values of $T P$ need to be calculated by using the same constraints (Supplementary Section 3). Then the index $P_{s c}$ can be scaled into the range of 0 to 1 by using the maximum and minimum value of $T P$.

To achieve trade-offs among multiple objectives and make quantitative assessments for solutions, two bilinear average metrics, " $F E W_{S 1}$ " and " $F E W_{S 2}$ " metric, are formulated in Eq. 4 and Eq.5.

$$
\begin{gathered}
F E W_{S 1}=\frac{1}{2}\left(F_{s c} E_{s c}+E_{s c} W_{s c}+W_{s c} F_{s c}\right) \sin 120^{\circ} \\
F E W_{S 2}=\frac{1}{2}\left(P_{s c} F_{s c}+F_{s c} E_{s c}+E_{s c} W_{s c}+W_{s c} E n_{s c}+E n_{s c} P_{s c}\right) \sin 72^{o}
\end{gathered}
$$


The metric $F E W_{S 1}$ integrates all the three main indexes of the FEW nexus by using them to construct a triangular spider map, presented in Fig. 4a. Therefore, the objective function of the optimization problem can be simply converted to the maximization of the graph area combined by the three indexes, and the solution can be easily visualized on the spider plot. To create a metric that integrates additional decision elements such as profit and environmental cost the $F E W_{S 2}$ metric was formulated in Eq. 5 and the spider plot resulting from this index is presented in Fig. 4b. Similarly, the multi-objective optimization problem can be converted to the maximum problem of the pentagonal area in the spider map. Preliminary results from previous work have verified the effectiveness (Avraamidou et al., 2018a,b; Nie et al., 2018; Mroue et al., 2019).
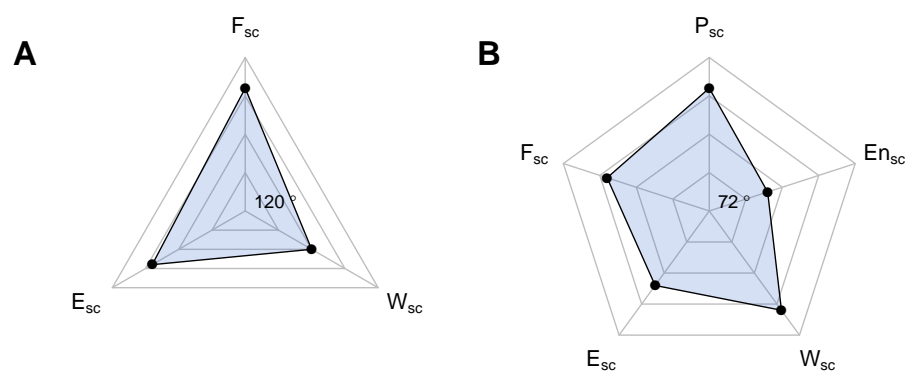

Figure 4: Representation of the composite metric. A: $F E W_{S 1}$; B: $F E W_{S 2}$

\section{Results}

We construct a crop-livestock land use system by selecting three crops and three livestock throughout three land types among 16-year climate conditions at Yucheng Station (Fig. S2, Table S1). The proposed framework solves the land use problem through three sequential steps including design, modeling, and optimization based on FEW-Nexus in the system, which is a decomposed strategy for solving the overall decision-making problem (see Section 3).

We represent the initial configuration of the crop-livestock land use system with a superstructure network in step 1 of the framework (Fig. 3). Fig. 5 shows two optimal superstructures of the system based on our trade-off solutions, which are generated by respectively taking the two FEW metrics $F E W_{S 1}$ and $\left.F E W_{S 2}\right)$ as integrated objectives to solve the multi-objective optimization problem. The optimal superstructures show the general decisions of production units, land allocation, technology options, and FEW pathways in the system.

In step 2, the production units of crop and livestock in the system are modeled. The proposed adaptive data-driven modeling methods (Section 3.2) is used to construct crop yield predictive models based 

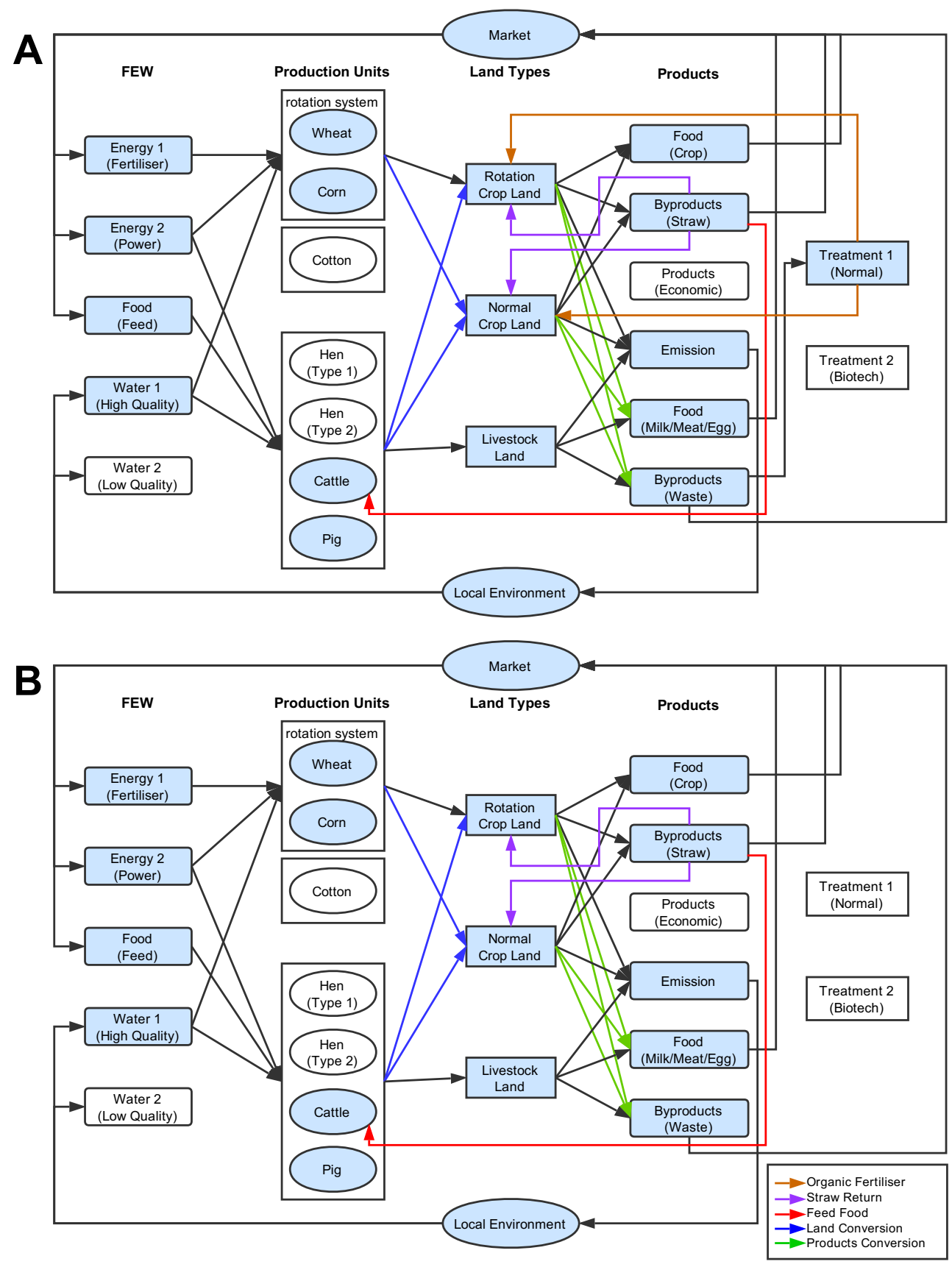

Figure 5: Optimal superstructure for the crop-livestock land use system based on trade-offs. The blue components are the active units. (A) Optimal superstructure based on the trade-off from metric $F E W_{S 1}$ based optimization. (B) Optimal superstructure based on the trade-off from metric $F E W_{S 2}$ based optimization. 
the cotton predictive model under climate condition 1 as an illustration of good-of-fit performance. Fig. 6A shows that the adaptation strategies can efficiently reduce the error ratios when iteratively adding new reliable input-output data samples, where strategy 2 has more robust performance. Fig. $6 \mathrm{~B}$ shows the final fit performance of the predictive model after limited adaptation times, illustrating the mix-weighted predictive model and the models with single types are good enough to simulate production behaviors (error ratio $<2 \%$ ). By using the adaptation strategies, we can keep on improving the fit performance with new data. Fig. S4A shows the relative robust contribution of different single model types to the final mix-weighted predictive model when the adaptation iterations increase (i.e., the weights for different types of model vary over narrow ranges). In general, the predictive model of crop production units describe the relations between input energy (fertiliser) and water and output food yield (Fig. S4B). The optimal parameters, weights, and final error rates for the crop production mix-weighted predictive models in three climate conditions are reported by Table S8.
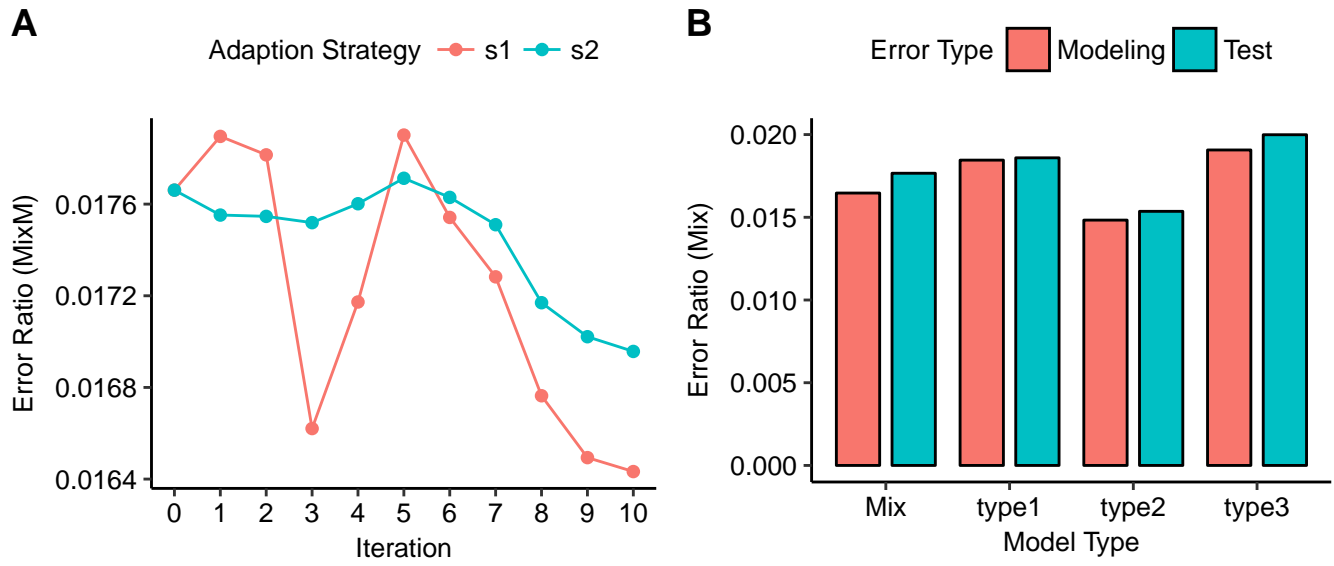

Figure 6: Good-of-fit performance of adaptive data-driven modeling (e.g. cotton predictive model under climate condition 1). (A) Error ratios of the predictive model based on two adaptation strategies. Strategy 1 (s1) adds new samples without adjusting bad samples, strategy 2 (s2) adds new samples and removes an equal number of bad samples simultaneously. (B) Comparisons of final error ratios of the predictive models. The predictive model is a mix-weighted model based on integration of type1 (linear), type2 (exponential), and type3 (quadratic). The modeling and test error ratios are calculated by using the cross-validation method.

The livestock production units are modeled with linear and piecewise functions (see Supplementary Section 4.1). All the functions show the relations between production time and food yield, as the use of input energy and water have been standardized by using known feed formulas (Table S3). Fig. S5 takes milk production and pig growth as examples to report the fit performance. The results show that the fitted data can match the reference data very well $\left(R^{2}>0.99\right)$. 
Interests of different stakeholders are converted into multiple objectives including total profit $(T P)$, total food production $(T F)$, total energy use $(T E)$, total water use $(T W)$ and total environmental penalty $(T E n)$. In step 3, two FEW metrics $\left(F E W_{S 1}\right.$ and $\left.F E W_{S 2}\right)$ are designed as the integrated objectives of the above multiple objectives and are solved as mixed integer nonlinear programming problems (MINLP) efficiently (Section 3.3. Table 2 summarizes the annual trade-off solutions based on two FEW metrics and five individual objectives, which include optimal objective values, diverse decisions for land allocation, food output, energy and water use, and choices of resources and treatment techniques in the system. The optimal solutions allow options for material recycles in the system for different objectives.

Table 2: Optimal solutions for multi-objective optimization (condition 1)

\begin{tabular}{|c|c|c|c|c|c|c|c|}
\hline & Max TP & Max TF & Max TE & Max TW & Max TEn & $\operatorname{Max} F E W_{S 1}$ & $\operatorname{Max} F E S_{S 2}$ \\
\hline \multirow[t]{2}{*}{ Cropland grid } & wheat-corn $(2)$ & wheat-corn $(2)$ & wheat-corn(1) & wheat-corn(1) & wheat-corn(1) & wheat-corn $(2)$ & wheat-corn $(2)$ \\
\hline & & & $\operatorname{cotton}(1)$ & $\operatorname{cotton}(1)$ & $\operatorname{cotton}(1)$ & & \\
\hline \multirow[t]{2}{*}{ Livestock land grid } & cattle(1) & cattle(1) & cattle(1) & cattle(1) & cattle(1) & cattle(1) & $\operatorname{cattle}(1)$ \\
\hline & $\operatorname{pig}(1)$ & $\operatorname{pig}(3)$ & $\operatorname{pig}(1)$ & $\operatorname{pig}(1)$ & $\operatorname{pig}(1)$ & $\operatorname{pig}(1)$ & $\operatorname{pig}(1)$ \\
\hline Profit (Yuan) & $1.54 \mathrm{E}+05$ & $-3.06 \mathrm{E}+05$ & $-1.26 \mathrm{E}+06$ & $-1.26 \mathrm{E}+06$ & $-1.26 \mathrm{E}+06$ & $5.29 \mathrm{E}+04$ & $1.01 \mathrm{E}+04$ \\
\hline Food production (MJ) & $3.55 \mathrm{E}+06$ & $4.01 \mathrm{E}+06$ & $7.15 \mathrm{E}+05$ & $7.15 \mathrm{E}+05$ & $7.15 \mathrm{E}+05$ & $3.01 \mathrm{E}+06$ & $8.37 \mathrm{E}+05$ \\
\hline Energy use (MJ) & $3.97 \mathrm{E}+06$ & $6.42 \mathrm{E}+06$ & $4.77 \mathrm{E}+05$ & $4.77 \mathrm{E}+05$ & $4.77 \mathrm{E}+05$ & $1.30 \mathrm{E}+06$ & $3.92 \mathrm{E}+05$ \\
\hline Water use $(\mathrm{t})$ & $1.65 \mathrm{E}+04$ & $2.69 \mathrm{E}+05$ & $1.46 \mathrm{E}+03$ & 40 & 40 & $1.53 \mathrm{E}+04$ & $3.10 \mathrm{E}+03$ \\
\hline Environment Penalty (Yuan) & $6.80 \mathrm{E}+04$ & $9.88 \mathrm{E}+4$ & $1.40 \mathrm{E}+03$ & $1.40 \mathrm{E}+03$ & $1.40 \mathrm{E}+03$ & $2.61 \mathrm{E}+04$ & $6.70 \mathrm{E}+03$ \\
\hline Irrigation water & high quality & high quality & high quality & - & - & high quality & high quality \\
\hline \multirow[t]{3}{*}{ Crop byproduct use } & feed $(100 \%)$ & feed $(99.4 \%)$ & feed $(5.6 \%)$ & feed $(5.6 \%)$ & feed $(5.6 \%)$ & $\operatorname{return}(0.1 \%)$ & return $(3 \%)$ \\
\hline & & $\operatorname{sell}(0.6 \%)$ & $\operatorname{sell}(94.4 \%)$ & $\operatorname{sell}(94.4 \%)$ & $\operatorname{sell}(94.4 \%)$ & feed $(2.2 \%)$ & feed $(3 \%)$ \\
\hline & & & & & & $\operatorname{sell}(97.7 \%)$ & $\operatorname{sell}(94 \%)$ \\
\hline \multirow[t]{2}{*}{ Livestock byproduct use } & $\operatorname{sell}(100 \%)$ & $\operatorname{sell}(97.2 \%)$ & $\operatorname{sell}(100 \%)$ & $\operatorname{sell}(100 \%)$ & $\operatorname{sell}(100 \%)$ & $\operatorname{sell}(62.4 \%)$ & $\operatorname{sell}(100 \%)$ \\
\hline & & $\operatorname{return}(2.8 \%)$ & & & & $\operatorname{return}(37.6 \%)$ & \\
\hline Bio-technology treatment & no & no & no & no & no & no & no \\
\hline Feedfood source & market & market & cropland & cropland & cropland & market & market \\
\hline Feedstraw source & cropland & cropland & cropland & cropland & cropland & cropland & cropland \\
\hline
\end{tabular}

TP: total profit; TF: total food production; TE: total energy use; TW: total water use; TEn: total environmental penalty.

Fig. 7 compares the trade-off solutions with individual objective based solutions under climate condition 1. Barplots in Fig. 7A compare the relative optimal determined values including production cost, food yield, energy use, water use and environmental penalty based on different solutions. Specifically, the solutions based on minimizing energy use, water use and environmental penalty ( $T E, T W$ and $T E n$ ) have the lowest relative values compared with other objective-based solutions. The solutions based on maximizing total profit and food production $(T F$ and $T P)$ achieve a high level of food output but also consume large amounts of resources and make enormous negative impacts on the environment. 
As for the trade-off solutions by maximizing the FEW-metrics $\left(F E W_{S 1}\right.$ and $\left.F E W_{S 2}\right)$, they can achieve more food yield (compare with the TE, TW and TEn based solutions) while using fewer resources (compare with the $T F$ and $T P$ based solutions). Looking into the compositions of all the considered factors, all the solutions suggest that crop productions rather than livestock productions make greater contributions to food output, water and energy use, and environmental impacts. Fig. 7B shows the solutions of land allocation for different objectives, which illustrate using less land and keeping diversity of land use are better strategies than using all the land to produce food. To compare and assess all the solutions comprehensively, Fig. 7C shows the results in the spider maps with five indexes, which quantitatively represent the five individual objectives respectively. The performance of FEW metric based solutions $\left(F E W_{S 1}\right.$ and $\left.F E W_{S 2}\right)$ is shown in the first and second spider map, illustrating more balanced designs for decision making, since they consider several interests of stakeholders at the same time (Section 3.3).

We also analyze the FEW Nexus in the system by taking optimal solutions under climate condition 1. Fig. S6 and Fig. S7 show that the livestock productions will be stopped at a different time based on different objectives, and all the solutions select to allocate livestock land to cattle and pig production. Note that minimizing energy, water and environmental penalty will get the same stop times with the proposed tradeoff solutions from maximizing the graph area, which is indicated by $F E W_{S 1}$ and $F E W_{S 2}$ (Fig. S7C). Fig. S8 and Fig. S9 describe the objective-related routes for three main materials in the system. The three materials are feed straw for feeding cattle, fertiliser for all the crop production, and feed food for feeding all the livestock. These different material supply routes indicate that not all the advanced technologies and resource reuse are always necessary for systematic decision-making. For instance, the biotechnology for treating livestock waste and organic fertiliser return are not selected for the tradeoff decisions (Fig. S8). Even for the solutions that choose organic fertiliser return as one kind of fertiliser for crop production, the chemical fertiliser still play the key role and cannot be totally replaced (Fig. S8A, Fig. S9B).

In this study, the lowest food yield at normal climate condition (Condition 1, shown in Fig. S2) are used as the lower constraint of food demand in order to compare climate-related performance at the same basis. Fig. 8A present the comparisons of relative food yield, energy and water use, environmental penalty and production cost for the trade-off solutions at the three climate conditions. The results show that generally production at years in condition 1 may achieve more yield and consume fewer resources, and consistent decisions can be made for land allocation in different conditions (Fig. 8B). The solutions are also evaluated by the FEW metrics (Fig. 8C), which show that the trade-off solutions 


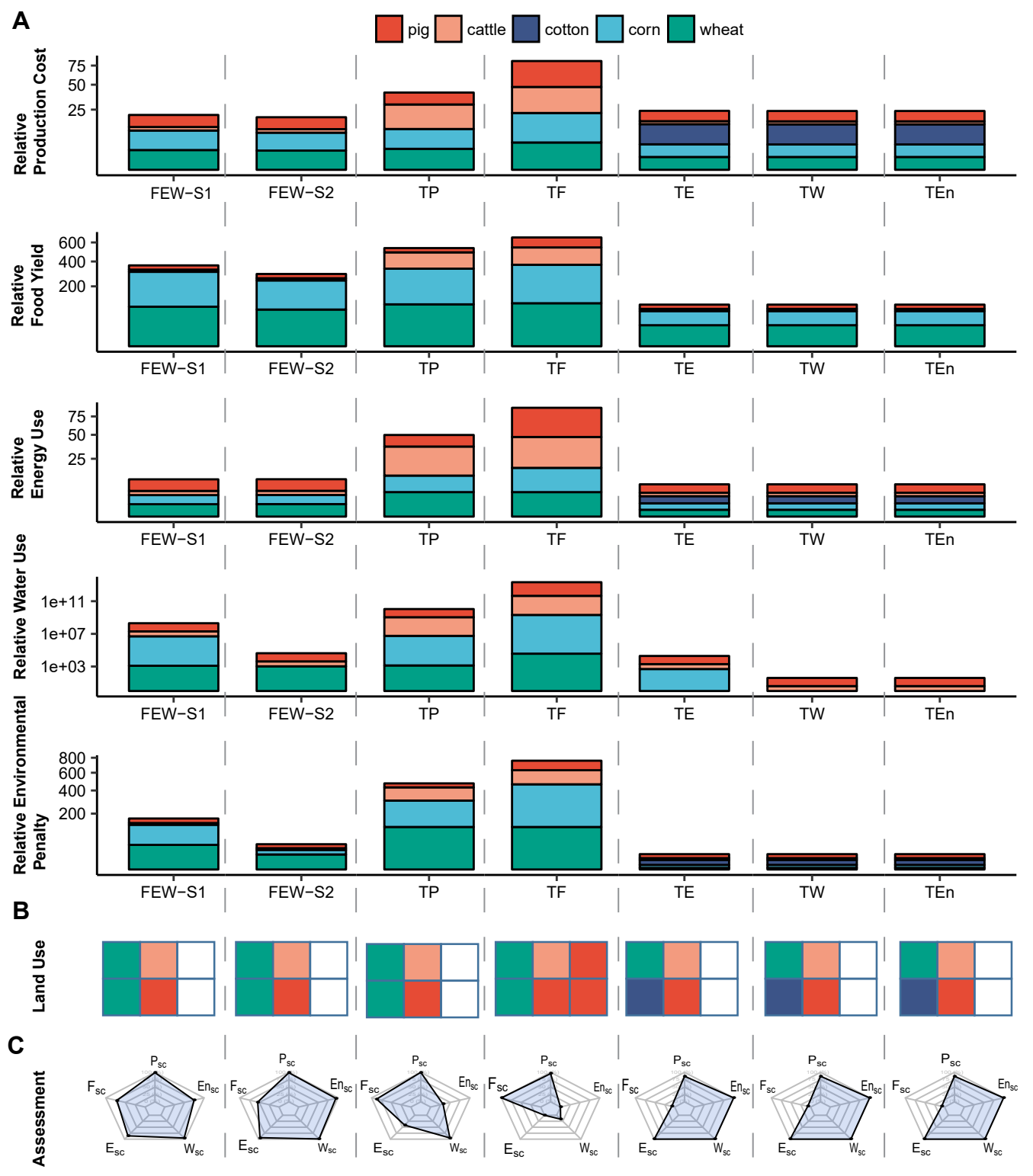

Figure 7: Comparison and assessment of multiple solutions under climate condition 1. (A) Optimal solutions for multiple objectives including FEW metrics ( $F E W_{S 1}$ and $F E W_{S 2}$ ), and five individual objectives including total profit (TP), total food production (TF), total energy use (TE), total water use (TW), and total environmental penalty (TEn). FEW 1 is an integrated index by combining the objectives of total food, energy and water; $F E W_{S 2}$ is an integrated index by combining all the five individual objectives. The relative optimal determined value and compositions of production cost, food yield, energy use, water use, and environmental penalty are compared for the seven objectives. (B) Optimal land allocations for different objective based optimization. Specifically, the green color represent the land grids allocated to wheat-corn rotation system, and there is no land competition for wheat and corn production. The white color means the grids are unused. (C) Solution comparison for different objectives. The indexes for five objectives are represented as: Profit - $P_{s c}$, Food - $F_{s c}$, Energy - $E_{s c}$, Water - $W_{s c}$, Environment - $E n_{s c}$. 
perform robust across different conditions.

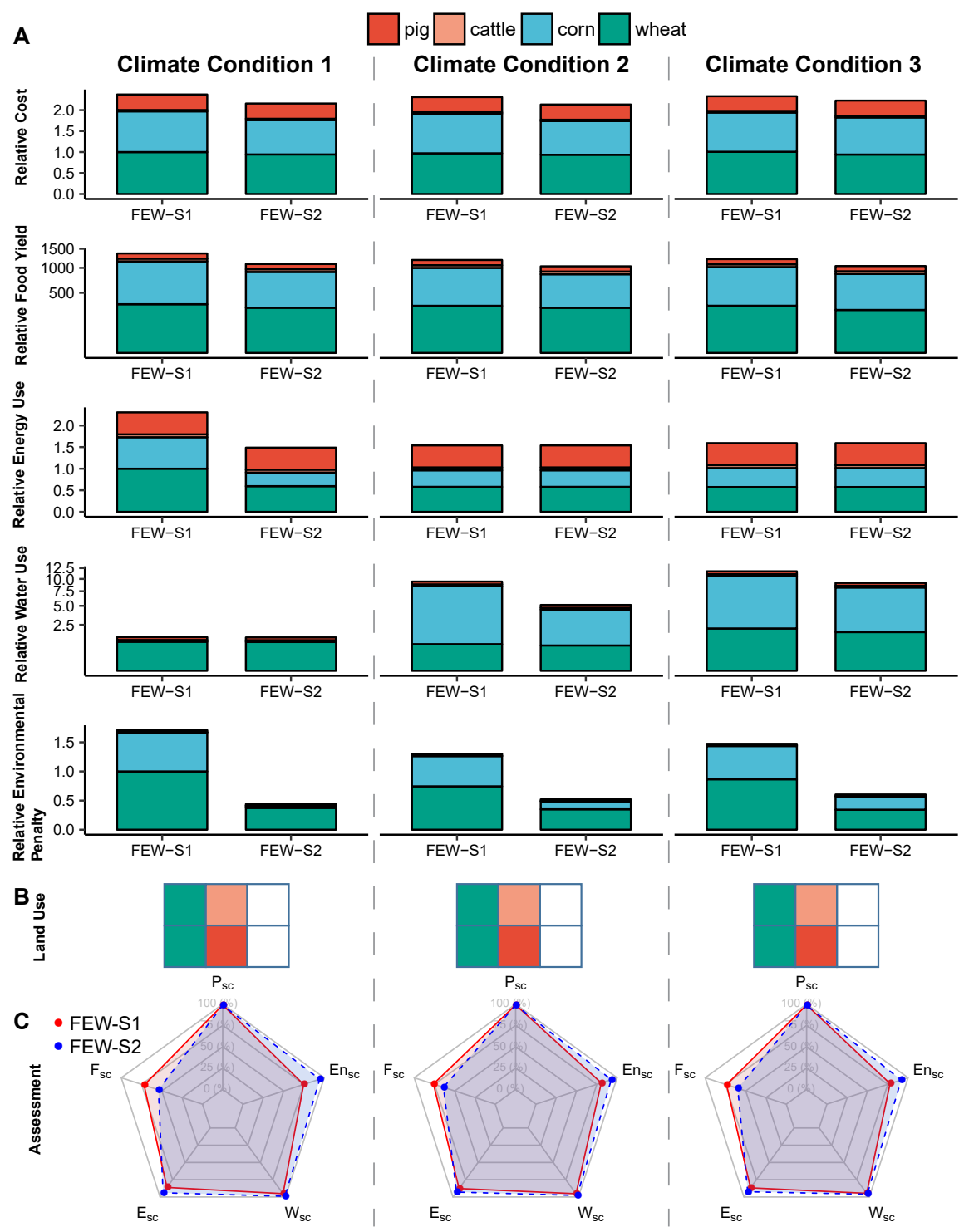

Figure 8: Comparison and assessment of trade-off solutions under different climate conditions. (A) Trade-off solutions are achieved by respectively taking $F E W_{S 1}$ and $F E W_{S 2}$ as objectives under three climate conditions. $F E W_{S 1}$ is an integrated index by combining the objectives of total food, energy and water; $F E W_{S 2}$ is an integrated index by combining all the five single objectives. The relative optimal determined value and compositions of production cost, food yield, energy use, water use, and environmental penalty are compared for the five objectives. (B) Optimal land allocations for FEW metric based optimization under three climate conditions. Specifically, we use the green color of wheat to represent the land grids allocated to wheat-corn rotation system. The white color means the grids are unused. For each climate condition, the $F E W_{S 1}$ and $F E W_{S 2}$ based solutions have the same solutions for land allocation. (C) Comparison of trade-off solutions under different climate conditions. The red color represent $F E W_{S 1}$ based solution, the blue color represent $F E W_{S 2}$ based solution. The indexes for five objectives are represented as: Profit - $P_{s c}$, Food $-F_{s c}$, Energy $-E_{s c}$, Water $-W_{s c}$, Environment - $E n_{s c}$. 


\section{Discussion}

The case study illustrates that the proposed framework can achieve trade-off solutions to inform and assist decision-makers by following three steps: design, modeling, and optimization. Specifically, the land use system can be designed as a superstructure network by analyzing the FEW flow and nexus; multiple production components in the network can be simulated by using an adaptive datadriven modeling method for yield prediction under different climate conditions; and the final trade-off solutions for diverse stakeholders can be achieved based on the previous superstructure and models by using a FEW metric based optimization method. Our results show that the proposed framework provides an effective and consistent methodology for improving, selecting, and assessing systematic decisions for land use, which is an innovative try for constructing generic workflows for systematic land use considering quantitative FEW-Nexus, effective integration of data and models, and standardized metrics for solution selection and assessment.

Superstructure optimization based approaches have been proven to be cost effective and energy efficient for industrial process synthesis and analysis (Yuan et al., 2013). However, its application for agricultural process integration is still in the infancy. Food-Energy-Water Nexus (FEW-N), as presented in this study, is what makes the superstructure design possible (Hang et al., 2016). From the systematic view of FEW-N, we simplify the complicated agricultural system based on input and output FEW flow and use the interdependence among diverse process units to combine them, which will generate all the possible pathways for the system. Based on the superstructure optimization formulation with desired objectives such as maximum food production or minimum water use, we can find optimal process topology network without any unnecessary connections and the operating parameters for each units in the system simultaneously.

Recent developments in agricultural modeling and optimization have created increased capability for the management of land use via complicated modeling methods with more parameters (Goel et al., 2007). However, the responses of productivity vary widely across different model types and region/climate specific data, reflecting differences in the realistic gap between optimal potential yield and real yield. The results in the Modeling step of our framework show that the proposed models have the robust performance based on limited region and climate specific data compared to previous studies (Humblot et al., 2017). This is because the proposed modeling methods use a mix-weighted methods to balance the bias performance from different model types, and provides adaptation strategies to keep on improving the fit performance of region and climate specific models generated by limited data-driven modeling methods. The characters of the our modeling methods illustrate that we can control the neg- 
ative impact on data limitations and simplify complicated scientific models for realistic use, which are especially important for developing countries who are lacking systematic agricultural databases with local details. The adaptation strategies also provide effective ways for improving predictive models and accumulating available data.

Agricultural land is not only farming entity but also known as supplying various products and services to multiple stakeholders (Van Ittersum et al., 2008). Such land management is an evolving outcome of unremitting negotiation and frequent conflicting interests among the stakeholders. The means by which conflicts are settled will be subject to varying supply and demand of FEW, and will vary depending on regions and climate conditions (Daher et al., 2019). Thus, the compromise of different stakeholders, and the robust performance with uncertainties are crucially important due to their impacts on systematic decision-making for land use. By using the FEW metric based optimization method provided by the framework, trade-offs among diverse stakeholders can be achieved most effectively and consistently. In the optimization step, each of the stakeholder's objective is formulated and normalized by taking their own maximum and minimum optimal values as boundaries. Therefore, all the objectives can be transformed into the same scale (e.g., from 0 to 1) by using their own boundaries, which provides a consistent basis for comparison and evaluation. All of these scaled objectives can be merged together by taking the FEW metric as the integrated objective, which can be visualized in spider graphs. We find that the FEW metric based solutions always show more balanced designs since it can effectively facilitate the simultaneous farming of diverse goals from stakeholders. Based on integrated use of previous FEW data, models, and alternative pathways in the superstructure, the assessment results show that the FEW metric based methods also have robust performance when considering different climate scenarios, since the framework can adjust the operations in the system to keep consistent performance of the land use decisions.

There is a need for developing methodologies for quantifying policy coherence through quantifying the impact of proposed policies across different sectors based on multiple scales, and identify the compatibility of current institutional setup and sectional interactions considering the nature of FEW resource systems and their interconnections (Daher et al., 2019). The proposed framework designs a series of FEW indexes for objectives from different stakeholders, and finally offers a generic metric for evaluating and comparing different solution strategies, which provides possibilities for policy-makers to adjust policies across different stakeholders, production sectors, and time periods. 


\section{Limitations and future work}

It is important to discuss some limitations of the developed framework and the potential implications of the modeling and optimization methods. First, we assume the schedules calculated base on frequency analysis as the "near-optimal" schedules for crop production units. Whilst this choice reduces the computational demands of the data-driven modeling, it may result to an underestimation of the real potential yield. Future modeling work should seek to model production under dynamic schedules and expect to solve the optimization problem of minimizing the gap between simulating yield and real potential yield based on optimal schedules.

A further limitation of the framework is the distribution problem. Our current work focuses on the allocated amount of land and FEW resources for different production units with a given area. Furthermore, the spatial distribution of different production objects in the land graph has not yet been considered. In the future, this can be important for the optimization of supply chains in the land use system. We also expect to integrate methods, such as graph theory, to consider the spatial distribution of land, FEW, and facilities.

\section{Conclusion}

Meeting the demand for food, energy, and water on a diminishing supply of agricultural land in the world without negative environmental impact is a major scientific challenge facing humanity. Despite the increasing techniques, data and models, a unified framework to integrate them and make trade-offs is lacking. To this end, we propose a framework to facilitate decision-makings based on a DesignModeling-Optimization procedure. Taking an experimental station in China as a model system, our framework quantifies the related Food-Energy-Water Nexus, explores trade-offs for diverse stakeholders, identifies sustainable pathways for meeting both nature conservation goals and human demand, and provides benchmarks for assessing strategies directing alternative pathways. Inspired by the multi-scale integration, our methodology should have general utility in complex agricultural systems.

\section{Acknowledgement}

The authors gratefully acknowledge financial supports from STS Project of Chinese Academy of Sciences [KFJ-EW-STS-054-3], the Program of China Scholarship Council [201604910976], the National Natural Science Foundation of China [61603370], National Science Foundation under Grant Addressing 
Decision Support for Water Stressed FEW Nexus Decisions [1739977], and Texas A \& M Energy Institute.

\section{References}

Albrecht, T. R., Crootof, A., \& Scott, C. A. (2018). The water-energy-food nexus: A systematic review of methods for nexus assessment. Environmental Research Letters, 13, 043002.

Alexandratos, N., Bruinsma, J. et al. (2012). World agriculture towards 2030/2050: the 2012 revision. Technical Report ESA Working paper FAO, Rome.

Asseng, S., Ewert, F., Rosenzweig, C., Jones, J., Hatfield, J., Ruane, A., Boote, K. J., Thorburn, P. J., Rötter, R. P., Cammarano, D. et al. (2013). Uncertainty in simulating wheat yields under climate change. Nature Climate Change, 3, 827.

Avraamidou, S., Beykal, B., Pistikopoulos, I. P., \& Pistikopoulos, E. N. (2018a). A hierarchical FoodEnergy-Water Nexus (FEW-N) decision-making approach for land use optimization. In Computer Aided Chemical Engineering (pp. 1885-1890). Elsevier volume 44.

Avraamidou, S., Milhorn, A., Sarwar, O., \& Pistikopoulos, E. N. (2018b). Towards a quantitative food-energy-water nexus metric to facilitate decision making in process systems: A case study on a dairy production plant. In Computer Aided Chemical Engineering (pp. 391-396). Elsevier volume 43.

Beinat, E., \& Nijkamp, P. (1998). Multicriteria analysis for land-use management volume 9. Springer Science \& Business Media.

Bergstrom, J. C., Goetz, S. J., \& Shortle, J. S. (2013). Land use problems and conflicts: Causes, consequences and solutions. Routledge.

Bertran, M.-O., Frauzem, R., Sanchez-Arcilla, A.-S., Zhang, L., Woodley, J. M., \& Gani, R. (2017). A generic methodology for processing route synthesis and design based on superstructure optimization. Computers $\&$ Chemical Engineering, 106, 892-910.

Bhosekar, A., \& Ierapetritou, M. (2017). Advances in surrogate based modeling, feasibility analysis and and optimization: A review. Computers $\&$ Chemical Engineering, .

Chen, Z., Lu, C., \& Fan, L. (2012). Farmland changes and the driving forces in Yucheng, North China Plain. Journal of Geographical Sciences, 22, 563-573. 
Chiandussi, G., Codegone, M., Ferrero, S., \& Varesio, F. E. (2012). Comparison of multi-objective optimization methodologies for engineering applications. Computers $\&$ S Mathematics with Applications, 63, 912-942.

Daher, B., Lee, S.-H., Kaushik, V., Blake, J., Askariyeh, M. H., Shafiezadeh, H., Zamaripa, S., \& Mohtar, R. H. (2019). Towards bridging the water gap in texas: A water-energy-food nexus approach. Science of the Total Environment, 647, 449-463.

Daher, B., Mohtar, R. H., Pistikopoulos, E. N., Portney, K. E., Kaiser, R., \& Saad, W. (2018). Developing socio-techno-economic-political (STEP) solutions for addressing resource nexus hotspots. Sustainability, 10, 512 .

Dargin, J., Daher, B., \& Mohtar, R. H. (2018). Complexity versus simplicity in water energy food nexus (wef) assessment tools. Science of The Total Environment, .

Dhaubanjar, S., Davidsen, C., \& Bauer-Gottwein, P. (2017). Multi-objective optimization for analysis of changing trade-offs in the Nepalese Water-Energy-Food Nexus with hydropower development. Water, 9, 162.

D’Odorico, P., Davis, K. F., Rosa, L., Carr, J. A., Chiarelli, D., Dell'Angelo, J., Gephart, J., MacDonald, G. K., Seekell, D. A., Suweis, S. et al. (2018). The global food-energy-water nexus. Reviews of Geophysics, .

El-Gafy, I. (2017). Water-food-energy nexus index: analysis of water-energy-food nexus of crops production system applying the indicators approach. Applied Water Science, 7, 2857-2868.

Ellis, E. C., \& Ramankutty, N. (2008). Putting people in the map: anthropogenic biomes of the world. Frontiers in Ecology and the Environment, 6, 439-447.

Fang, Q., Yu, Q., Wang, E., Chen, Y., Zhang, G., Wang, J., \& Li, L. (2006). Soil nitrate accumulation, leaching and crop nitrogen use as influenced by fertilization and irrigation in an intensive wheatmaize double cropping system in the North China Plain. Plant and Soil, 284, 335-350.

FAO, U. (2009). How to feed the world in 2050. In Rome: High-Level Expert Forum.

Flammini, A., Puri, M., Pluschke, L., Dubois, O. et al. (2017). Walking the nexus talk: assessing the water-energy-food nexus in the context of the sustainable energy for all initiative. FAO. 
Frank, M. D., Beattie, B. R., \& Embleton, M. E. (1990). A comparison of alternative crop response models. American Journal of Agricultural Economics, 72, 597-603.

Garcia, D. J., \& You, F. (2016). The water-energy-food nexus and process systems engineering: a new focus. Computers \&6 Chemical Engineering, 91, 49-67.

Goel, T., Haftka, R. T., Shyy, W., \& Queipo, N. V. (2007). Ensemble of surrogates. Structural and Multidisciplinary Optimization, 33, 199-216.

Hang, M. Y. L. P., Martinez-Hernandez, E., Leach, M., \& Yang, A. (2016). Designing integrated local production systems: a study on the food-energy-water nexus. Journal of Cleaner Production, 135, $1065-1084$.

Holzworth, D. P., Snow, V., Janssen, S., Athanasiadis, I. N., Donatelli, M., Hoogenboom, G., White, J. W., \& Thorburn, P. (2015). Agricultural production systems modelling and software: current status and future prospects. Environmental Modelling \& Software, 72, 276-286.

Humblot, P., Jayet, P.-A., \& Petsakos, A. (2017). Farm-level bio-economic modeling of water and nitrogen use: Calibrating yield response functions with limited data. Agricultural systems, 151, $47-60$.

van Ittersum, M. K., Cassman, K. G., Grassini, P., Wolf, J., Tittonell, P., \& Hochman, Z. (2013). Yield gap analysis with local to global relevancea review. Field Crops Research, 143, 4-17.

Jones, J. W., Antle, J. M., Basso, B., Boote, K. J., Conant, R. T., Foster, I., Godfray, H. C. J., Herrero, M., Howitt, R. E., Janssen, S. et al. (2017a). Brief history of agricultural systems modeling. Agricultural systems, 155, 240-254.

Jones, J. W., Antle, J. M., Basso, B., Boote, K. J., Conant, R. T., Foster, I., Godfray, H. C. J., Herrero, M., Howitt, R. E., Janssen, S. et al. (2017b). Toward a new generation of agricultural system data, models, and knowledge products: State of agricultural systems science. Agricultural systems, 155, 269-288.

Jones, J. W., Hoogenboom, G., Porter, C. H., Boote, K. J., Batchelor, W. D., Hunt, L., Wilkens, P. W., Singh, U., Gijsman, A. J., \& Ritchie, J. T. (2003). The DSSAT cropping system model. European journal of agronomy, 18, 235-265. 
Keairns, D., Darton, R., \& Irabien, A. (2016). The energy-water-food nexus. Annual review of chemical and biomolecular engineering, 7, 239-262.

Keating, B. A., Carberry, P. S., Hammer, G. L., Probert, M. E., Robertson, M. J., Holzworth, D., Huth, N. I., Hargreaves, J. N., Meinke, H., Hochman, Z. et al. (2003). An overview of apsim, a model designed for farming systems simulation. European journal of agronomy, 18, 267-288.

Linker, R., \& Sylaios, G. (2016). Efficient model-based sub-optimal irrigation scheduling using imperfect weather forecasts. Computers and electronics in agriculture, 130, 118-127.

McCarl, B. A., Yang, Y., Schwabe, K., Engel, B. A., Mondal, A. H., Ringler, C., \& Pistikopoulos, E. N. (2017a). Model use in WEF nexus analysis: a review of issues. Current Sustainable/Renewable Energy Reports, 4, 144-152.

McCarl, B. A., Yang, Y., Srinivasan, R., Pistikopoulos, E. N., \& Mohtar, R. H. (2017b). Data for WEF nexus analysis: a review of issues. Current Sustainable/Renewable Energy Reports, 4, 137-143.

Misener, R., \& Floudas, C. A. (2014). Antigone: algorithms for continuous/integer global optimization of nonlinear equations. Journal of Global Optimization, 59, 503-526.

Mohtar, R. H., \& Daher, B. (2018). Lessons learned: Creating an interdisciplinary team and using a nexus approach to address a resource hotspot. Science of The Total Environment, .

Mohtar, R. H., Shafiezadeh, H., Blake, J., \& Daher, B. (2019). Economic, social, and environmental evaluation of energy development in the eagle ford shale play. Science of The Total Environment, $646,1601-1614$.

Montgomery, D. C., Peck, E. A., \& Vining, G. G. (2012). Introduction to linear regression analysis volume 821. John Wiley \& Sons.

Mroue, A. M., Mohtar, R. H., Pistikopoulos, E. N., \& Holtzapple, M. T. (2019). Energy portfolio assessment tool (EPAT): Sustainable energy planning using the wef nexus approach-texas case. Science of The Total Environment, 648, 1649-1664.

Nelson, G. C., Valin, H., Sands, R. D., Havlík, P., Ahammad, H., Deryng, D., Elliott, J., Fujimori, S., Hasegawa, T., Heyhoe, E. et al. (2014). Climate change effects on agriculture: Economic responses to biophysical shocks. Proceedings of the National Academy of Sciences, 111, 3274-3279. 
Nie, Y., Avraamidou, S., Li, J., Xiao, X., \& Pistikopoulos, E. N. (2018). Land use modeling and optimization based on food-energy-water nexus: a case study on crop-livestock systems. In Computer Aided Chemical Engineering (pp. 1939-1944). Elsevier volume 44.

Paul, C., Weber, M., \& Knoke, T. (2017). Agroforestry versus farm mosaic systems-comparing land-use efficiency, economic returns and risks under climate change effects. Science of the Total Environment, $587,22-35$.

Ramankutty, N., Mehrabi, Z., Waha, K., Jarvis, L., Kremen, C., Herrero, M., \& Rieseberg, L. H. (2018). Trends in global agricultural land use: implications for environmental health and food security. Annual review of plant biology, 69, 789-815.

Rathmann, R., Szklo, A., \& Schaeffer, R. (2010). Land use competition for production of food and liquid biofuels: An analysis of the arguments in the current debate. Renewable Energy, 35, 14-22.

Sayer, J., Sunderland, T., Ghazoul, J., Pfund, J.-L., Sheil, D., Meijaard, E., Venter, M., Boedhihartono, A. K., Day, M., Garcia, C. et al. (2013). Ten principles for a landscape approach to reconciling agriculture, conservation, and other competing land uses. Proceedings of the national academy of sciences, 110, 8349-8356.

Scanlon, B. R., Ruddell, B. L., Reed, P. M., Hook, R. I., Zheng, C., Tidwell, V. C., \& Siebert, S. (2017). The food-energy-water nexus: Transforming science for society. Water Resources Research, 53, 3550-3556.

Seppelt, R. (2016). Landscape-scale resource management: Environmental modeling and land use optimization for sustaining ecosystem services. Handbook of Ecological Models used in Ecosystem and Environmental Management, 3, 457.

Sims, R. (2011). Energy-smart food for people and climate. Technical Report UN Food and Agriculture Organisation.

Song, Y., Hou, D., Zhang, J., O'Connor, D., Li, G., Gu, Q., Li, S., \& Liu, P. (2018). Environmental and socio-economic sustainability appraisal of contaminated land remediation strategies: a case study at a mega-site in china. Science of The Total Environment, 610, 391-401.

Steduto, P., Hsiao, T. C., Raes, D., \& Fereres, E. (2009). Aquacropthe fao crop model to simulate yield response to water: I. concepts and underlying principles. Agronomy Journal, 101, 426-437. 
Stewart, T. J., Janssen, R., \& van Herwijnen, M. (2004). A genetic algorithm approach to multiobjective land use planning. Computers \& Operations Research, 31, 2293-2313.

Uen, T.-S., Chang, F.-J., Zhou, Y., \& Tsai, W.-P. (2018). Exploring synergistic benefits of WaterFood-Energy Nexus through multi-objective reservoir optimization schemes. Science of the Total Environment, 633, 341-351.

Van Ittersum, M. K., Ewert, F., Heckelei, T., Wery, J., Olsson, J. A., Andersen, E., Bezlepkina, I., Brouwer, F., Donatelli, M., Flichman, G. et al. (2008). Integrated assessment of agricultural systems-a component-based framework for the european union (seamless). Agricultural systems, 96, $150-165$.

Van Tra, T., Thinh, N. X., \& Greiving, S. (2018). Combined top-down and bottom-up climate change impact assessment for the hydrological system in the vu gia-thu bon river basin. Science of The Total Environment, 630, 718-727.

Vermeulen, S. J., Challinor, A. J., Thornton, P. K., Campbell, B. M., Eriyagama, N., Vervoort, J. M., Kinyangi, J., Jarvis, A., Läderach, P., Ramirez-Villegas, J. et al. (2013). Addressing uncertainty in adaptation planning for agriculture. Proceedings of the National Academy of Sciences, 110, 83578362.

Wang, J., \& Baerenklau, K. (2014). Crop response functions integrating water, nitrogen, and salinity. Agricultural water management, 139, 17-30.

Yuan, Z., Chen, B., \& Gani, R. (2013). Applications of process synthesis: Moving from conventional chemical processes towards biorefinery processes. Computers \& Chemical Engineering, 49, 217-229.

Zhang, J., Campana, P. E., Yao, T., Zhang, Y., Lundblad, A., Melton, F., \& Yan, J. (2018). The water-food-energy nexus optimization approach to combat agricultural drought: a case study in the united states. Applied Energy, 227, 449-464. 